\title{
Uma Taxonomia dos Tipos de Preconceito Enfrentados por Mulheres na Área de Tecnologia
}

\author{
Suellen Barros Ramos ${ }^{1}$, Karen da Silva Figueiredo ${ }^{2}$ \\ Instituto de Engenharia ${ }^{1}$ e Instituto de Computação ${ }^{2}$ - UFMT, Mato Grosso, Brasil ${ }^{1}$ \\ suellen.barrosramos@gmail.com, karen@ic.ufmt.br
}

\begin{abstract}
This article aims to discuss the discrimination faced by women in IT from a case study of a Brazilian campaign to raise awareness about the theme. This work performs a content analysis of the feedback received in social media about the campaign and presents a taxonomy of the kinds of prejudice suffered by women in IT based on categories from the literature of gender studies.

Resumo. O presente artigo tem como objetivo discutir a discriminação enfrentada por mulheres na TI a partir de um estudo de caso de uma campanha para a conscientização sobre o tema. Este trabalho realiza uma análise de conteúdo do feedback recebido nesta campanha e apresenta uma taxonomia das formas de preconceito sofridas pelas mulheres na TI baseada em categorias da literatura dos estudos de gênero.
\end{abstract}

\section{Introdução}

Os movimentos sociais são importantes na história da humanidade, eles foram e continuam a ser as alavancas da mudança social [Castells 2017]. Na sociedade da informação, estes movimentos ocupam espaços virtuais, ganham força e novos formatos por meio das redes sociais. O machismo como uma manifestação do desequilíbrio das relações de poder entre gêneros da cultura patriarcal [Vescio et al. 2010], atua em diversos campos da sociedade, inclusive na academia e mercado de trabalho de áreas tipicamente vistas como masculinas, como a computação [Cohoon et al. 2011].

Para Castells (2017), o poder é exercido programando redes de informações, e para alterar as relações de poder é preciso apropriar e reprogramar essas redes. Assim, surgem os movimentos protagonizados por mulheres da área de TI nas redes sociais a fim de denunciar o preconceito que estas vivenciam na área e formar redes de apoio na busca de soluções para o problema e uma reprogramação cultural e comportamental da área. Alguns exemplos internacionais são as campanhas ${ }^{1}$ : The Elephant in the Valley, \#IlookLikeAnEngineer e \#LeanInTogether que mobilizaram milhares de pessoas no mundo. No Brasil, a partir de 2015 apareceram as campanhas ${ }^{2}$ \#DeleteSeuPreconceito, \#SerMulherEm Tech, \#MachismoEmTI e a mais recente \#MeuLugarEmTI que surgiu na Campus Party Brasil 2018 após uma fala machista em uma palestra.

Estudar os movimentos sociais é de fundamental importância para construir uma compreensão política, fomentar a diversidade de ideias, orientar processos de inclusão social e conquistar direitos [Della Porta e Mattoni 1999]. Desta forma, o presente artigo tem como objetivo discutir a discriminação enfrentada por mulheres na TI a partir do

\footnotetext{
${ }^{1}$ www.elephantinthevalley.com, https://bit.ly/2IWkFUo, https://bit.ly/2rWBd3Y

${ }^{2}$ www.programaria.org/sermulheremtech/, https://machismoemti.com/, https://bit.ly/2IV2BtF
} 
estudo de caso da campanha \#DeleteSeuPreconceito. Este trabalho realiza uma análise de conteúdo [Bardin 1977] do feedback recebido nesta campanha e apresenta uma taxonomia das formas de preconceito sofridas pelas mulheres na TI baseada em categorias da literatura dos estudos de gênero.

\section{2. \#DeleteSeuPreconceito: um Estudo de Caso}

A campanha \#DeleteSeuPreconceito foi criada em junho de 2015 como um projeto fotográfico na rede social Facebook (www.facebook.com/deleteseupreconceito). A campanha consistia inicialmente num conjunto de 10 fotos de alunas e profissionais da área de TI acompanhadas de dispositivos eletrônicos com frases preconceituosas que já haviam escutado, a partir de então, houve a chamada para que outras mulheres compartilhassem suas histórias e novas fotos com o mesmo formato. Esta campanha foi escolhida para o estudo de caso do presente artigo por se tratar da primeira campanha popular sobre o tema no Brasil, tendo alcançado milhares de pessoas e sido divulgada pelas mídias e redes nacionais e internacionais.

A metodologia adotada foi coletar via script o texto dos comentários das fotos oficiais da campanha via e realizar uma análise de conteúdo manual segundo Bardin (1977) dos comentários, procurando identificar categorias para os tipos preconceito vivenciados pelas mulheres na TI. A coleta de dados foi realizada em março de 2018, somando 733 comentários em 9 fotos (1 foto original havia sido apagada) da campanha no Facebook. A Tabela 1 apresenta uma visão geral dos dados coletados sobre a campanha. A partir destes dados, foram selecionados para análise somente os comentários com mensagens preconceituosas sobre a mulher na TI, totalizando 343 amostras (47\% dos comentários). A sessão a seguir discute os achados da análise dos comentários por foto, destacando as categorias identificadas para a taxonomia.

Tabela 1. Dados da Campanha Delete Seu Preconceito por Foto

\begin{tabular}{|c|c|c|c|c|c|c|c|c|c|c|}
\hline Fotos & $\mathbf{1}$ & $\mathbf{2}$ & $\mathbf{3}$ & $\mathbf{4}$ & $\mathbf{5}$ & $\mathbf{6}$ & $\mathbf{7}$ & $\mathbf{8}$ & $\mathbf{9}$ & Total \\
\hline Comentários & 37 & 202 & 56 & 90 & 51 & 66 & 154 & 36 & 41 & $\mathbf{7 3 3}$ \\
\hline Curtidas & 677 & 1500 & 773 & 698 & 679 & 766 & 1100 & 730 & 629 & $\mathbf{7 5 5 2}$ \\
\hline Compartilhamentos & 18 & 111 & 14 & 14 & 13 & 71 & 57 & 19 & 15 & $\mathbf{3 3 2}$ \\
\hline
\end{tabular}

\section{Análise de Conteúdo}

“Ela não é Tech, ela é Louca” ou Gaslighting: A primeira foto carrega a frase "É melhor chamar um homem para te ajudar com isso!", ilustrando situações em que não acreditam na capacidade da mulher da TI, colocando a capacidade masculina acima da feminina apenas pelo gênero. Diversos comentários nesta foto seguem a linha do comentário a seguir "Sabe que eu não ouvi ninguém falar isso? Pq ninguém fala isso, isso é uma invenção criativa que as Feministas fazem para chamar a atenção!'. Este tipo de comentário é definido como gaslighting [Abramson 2014], i.e. a tentativa de deslegitimar o discurso de uma mulher alegando loucura, drama ou chamariz de atenção. O gaslighting na TI pode assumir formas diferentes formas, especialmente com relação a líderes e colegas de trabalho mulheres no desempenho do seu trabalho.

“O valor do hardware” ou Objetificação Feminina: A segunda foto e sua frase "Computação é como navio pirata: só tem homem e canhão!", tocam no ponto da objetificação feminina [Loughnan et al. 2010]. Os comentários analisados na foto 
abordam o mesmo tema, e.g. "vc quer ser bonita ou estudar exatas????”. A objetificação feminina despersonaliza a mulher e seus atributos intelectuais, valorizando apenas aspectos físicos da aparência que devem encaixar-se no padrão social da época. Quando a objetificação chega na TI, ela ataca mulheres dentro do padrão rotulando-as como belas ignorantes, e ataca mulheres fora do padrão, rotulando-as de feias competentes ou masculinizadas, como um motivo para escolherem a área. Essa forma de discriminação é extremamente opressora, pois não importa qual a aparência que possua, a mulher sempre será julgada por ela.

"Software pirata” ou Desqualificação Profissional e Bropriating: Nas terceira e nona fotos, com as respectivas legendas "Mas foi você que desenvolveu isso???" e "Mulher não tem lógica para ser programadora!" os comentários voltam no mesmo ponto da primeira foto, com diversos comentários que desqualificam o trabalho da mulher em TI apenas pelo seu gênero, e, na maioria das vezes, acompanhados da supervalorização da capacidade masculina, ou até mesmo o bropriating, i.e. quando um homem se apropria da autoria de algo feito por uma mulher. Alguns exemplos de comentários são: "Mas quem foi realmente, por que você não foi." e "Aí aparece um cara com um código com o mesmo resultado: Metade das linhas”.

“Chuva de haters" ou Misoginia: Na quarta foto, de legenda "Meninas precisam de gráficos, elas ficam perdidas com linhas de comando..." identificou-se a misoginia presente na área de TI. A misoginia é o ódio ou desprezo por mulheres apenas pelo seu gênero, como nos comentários: "o filha da $p(. .$.$) se tu não sabe usa linha de$ comando então desiste" e "sempre tinha um falando que eu estava trapaceando ou só me xingavam mesmo puta, feia, mulher-macho e outras coisas".

“O homem compilador” ou Mansplaining: $\mathrm{Na}$ análise dos comentários da quinta foto, os 10 comentários analisados retornam a temas como a desqualificação profissional e ao gaslighting. Já na sexta foto de legenda "Se fosse para programar, ela tinha nascido homem" escrita com pseudocódigo para a foto, aparecem diversos comentários do tipo mansplaining, i.e. situações em que um homem explica algo para uma mulher algo óbvio ou que ela já sabe, para transformar o pseudocódigo em código programável, como nos exemplos: "Vai dar erro de compilação" e "Consegui fazer o código dela rodar depois de colocar In dentro da string”.

“Faz programa?" ou Slut-shaming: Na sétima foto com a legenda "Achei que em Computação só tinha mulher feia." houve uma retomada da objetificação feminina na sua forma intensificada com o slut-shaming, i.e., uma forma de estigmatizar a mulher pela sua aparência ou comportamento através da vergonha e humilhação, e.g. "Deve ter uma GPU muito $f(. .$.$) derosa...".$

"Lugar de mulher é na cozinha” ou Mitos e Estereótipos: Na oitava foto com a frase "Mulheres não combinam com informática" surgem comentários como "Toda mulher precisa de terapia: ter a pia cheia de louça para lavar" e "Assim como homens combinam mais com engenharia civil quando o assunto é por a mão na massa" reforçando estereótipos machistas e mitos sobre os lugares e profissões que homens e mulheres devem ocupar, limitando suas escolhas e experiências de vida.

\section{Taxonomia dos Tipos de Machismo em TI}

Considerando o exposto, foi possível identificar 8 categorias a partir dos 343 comentários analisados. A Figura 1 apresenta a proporção de comentários do estudo de 
caso \#DeleteSeuPreconceito por categoria e a Figura 2 ilustra a taxonomia desenvolvida dos tipos de machismo em TI.

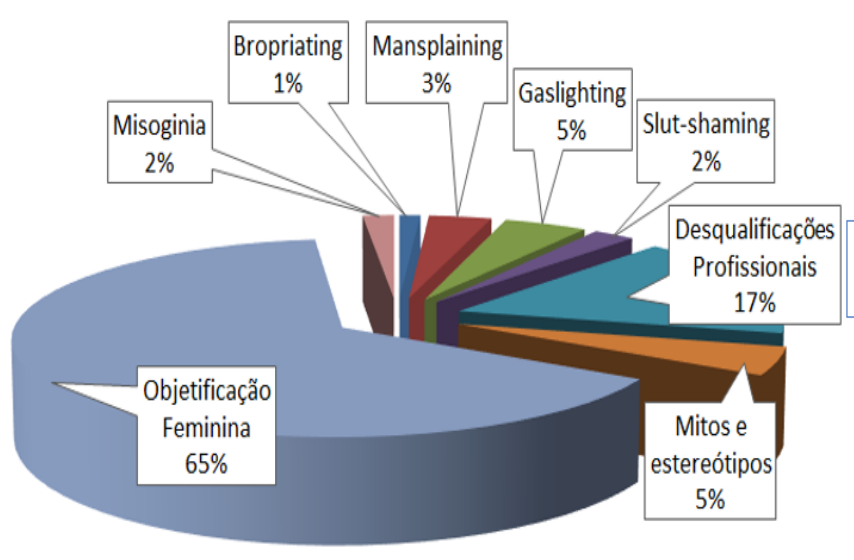

Figura 1. Classificação dos Comentários

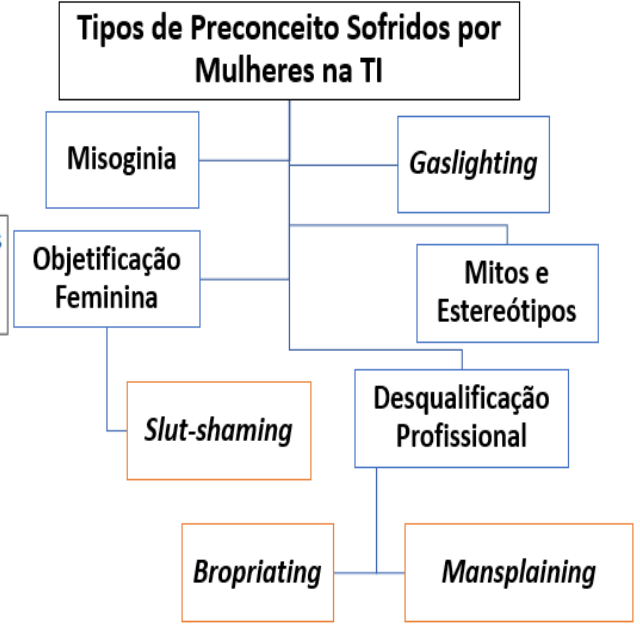

Figura 2. Taxonomia dos Tipos de Preconceito em TI

\section{Considerações Finais}

Machismo, misoginia e até racismo são problemas reais no passado e presente da computação [Hicks 2013]. Por meio da compreensão deste fenômeno é possível abrir as portas para a mudança social para a construção colaborativa de um campo mais inclusivo, diverso e sadio. Este trabalho contribuiu com um estudo de caso e a identificação de uma taxonomia dos tipos de preconceito vividos por mulheres na área de TI. As perspectivas futuras são de desenvolvimento de estratégias que possam ajudar a transformar esta realidade.

\section{Referências}

Abramson, K. (2014) "Turning up the Lights on Gaslighting", Philosophical perspectives, v. 28, n. 1, p. 1-30.

Bardin, L. (1977) “Análise de conteúdo”, Lisboa: edições 70 (1977): 225.

Castells, M. (2017) "Redes de indignação e esperança: movimentos sociais na era da internet”, Zahar.

Cohoon, J. et al. (2011) "Conflicted identities and sexism in computing graduate programs", Frontiers in Education Conference, IEEE, S1H-1-S1H-5.

Della Porta, D. e Mattoni, A. (1999) “Social movements”, John Wiley \& Sons, Inc.

Hicks, M. (2013) "De-brogramming the history of computing", IEEE History of Computing, v. 35 , n. 1 , p. $88-88$.

Loughnan, S. et al. (2010) "Objectification leads to depersonalization: The denial of mind and moral concern to objectified others", European Journal of Social Psychology, v. 40, n. 5, p. 709-717.

Vescio, T. K. et al. (2010) "Power and sexism.", The social psychology of power, p. 363-380, New York, Guilford Press. 